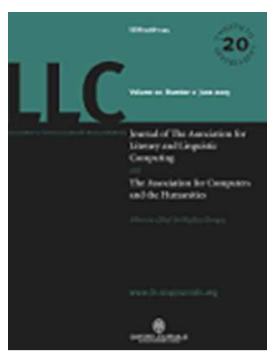

\title{
Theoretical considerations of applications and implications of concordance-based cloze tests
}

\begin{tabular}{|r|l|}
\hline Journal: & Literary and Linguistic Computing \\
\hline Manuscript ID: & LLC-2014-0015.R2 \\
\hline Manuscript Type: & Full Paper \\
\hline Date Submitted by the Author: & n/a \\
\hline Complete List of Authors: & $\begin{array}{l}\text { Kongsuwannakul, Kunlaphak; Suranaree University of Technology, School } \\
\text { of Foreign Languages }\end{array}$ \\
\hline Keywords: & Concordancing, cloze tests, applications, implications \\
\hline \multicolumn{2}{|l}{} \\
\hline
\end{tabular}

SCHOLARONE ${ }^{m}$

Manuscripts 
1

2

3

4

5

6

7

8

9

10

11

12

13

14

15

16

17

18

19

20

21

22

23

24

25

26

27

28

29

30

31

32

33

34

35

36

37

38

39

40

41

42

43

44

45

46

47

48

49

50

51

52

53

54

55

56

57

58

59

60

Title: Theoretical considerations of applications and implications of concordance-based cloze tests

Correspondence:

Kunlaphak Kongsuwannakul

School of Foreign Languages, Suranaree University of Technology

111 University Avenue, Muang, Nakhon Ratchasima 30000 Thailand

Email: kunlaphak@hotmail.com

Kunlaphak Kongsuwannakul http://mc.manuscriptcentral.com/llc 


\begin{abstract}
Concordance-based cloze (henceforth ConCloze) tests have rarely been researched over the past two decades. This paper explores some potentially practical applications of their manifold item formats to language testing. The formats can range from response-selected to response-constructed ones, all embracing Read's (2000) context-dependent vocabulary assessment and likely tapping into multiple aspects and components of Nation's (20010) word knowledge. These applications imply a fine-grained approach to vocabulary teaching and learning as well as wordknowledge profiling and evaluation in that the viability of this item type calls for attention to complex word-knowledge components rather than merely the usually recognized form-meaning dimension. This could in turn carry a broad implication for language-pedagogical paradigms in general and vocabulary assessment in particular. Moreover, as the ConCloze item formats may be constructed with the aid of corpus and concordance markings, the other implication is that corpora should be built purposively, and concordances annotated specifically yet multidimensionally. This will enable these corpus-linguistic tools to accommodate computer-based test construction and delivery of the ConCloze item type as well as other item types.
\end{abstract}

\title{
$1 \quad$ Introduction
}

The term concordance-based cloze test first appeared in Butler (1991). By definition, (generally, 'concordance' refers to is the list of examples of a particular word retrieved from a large collection of texts by a computer program, and 'cloze' a type of test in which test takers fill in the blanks of a passage with appropriate words. $)$. The Butler's test was a result of his service to the Certificate in Advanced English (CAE) by the then University of Cambridge Local Examinations Syndicate (UCLES). As illustrated in Fig. 1 below, his item has multiple sentence-completion prompts, all 
requiring the same word. Butler only trialed the 13-item test and encountered several technical problems. He admitted that the pilot study did not produce solid evidence of validity or reliability.

\author{
Fig. 1 One of Butler's (1991, p. 36) ConCloze item prototypes
}

\begin{abstract}
Scarcity issue. Although the item format is interesting and challenging, it gains little recognition for language testing, where (a subfield of educational measurement, usually dealing with assessing language ability and competence) are the objects of educational measurement. The formatIt is mentioned by very few researchers, let alone being researched. For example, Alderson (1996) envisaged possible uses of concordancing for test construction. He however did not even give any illustrative example. Flowerdew (1996) and Hargreaves (2000) reviewed Butler's idea, but did not carry out any research on it. Taylor and Barker (2008) only cited Hargreaves' suggestion of developing corpus-based test formats. Nonetheless, they did not provide any more detail about them. Similarly, Park (2014) — a very recent review paper on corpora and assessment—seemed to overlook the potential of concordances as test material. All it mentioned with regard to concordances was their use as a tool 1) informing course developers and teachers of various corpus-derived linguistic features, and 2) analyzing learner-language development by means of such language aspects as syntax, lexis, and cohesive devices in their language production. In short, the very potential of concordances as test material has been almost entirely missing from the literature in the course of their two-decade existence (i.e. since Butler (1991)).
\end{abstract}

The only tangible result of Butler's legacy is a small section in the CAE Use of English (Cambridge English Language Assessment, 2010b, p. 5). It has five items. Each item presents three sentence-completion prompts (in much the same way as those presented in Fig. 1) and claims to measure how well a test taker can control their grammar and vocabulary (Cambridge English Language Assessment, 2010a). While this construct may sound simple, it is completely opaque. It does not specify particular areas of language knowledge involved for test preparation and task 
performance (e.g. What components of grammar are concerned in the testing?). Nor does it indicate to the test takers and test users a specific intended interpretation of item responses (e.g. What does 'control one's grammar and vocabulary' mean? In what circumstances and to what extent is it valid?). Overall, the ConCloze item type is indeed far from being well-researched among language testers and thus has no systematic investigations into its potentially manifold formats and corresponding constructs. No other effort is known into exploring this item type, which could be simply because much of recent corpus-linguistic research for language pedagogy has usually been aimed at enriching language learning and instruction-e.g. investigation of authenticity in course textbooks (ClavelArroitia and Fuster-Márquez, 2014), validation of what learner vocabulary is truly frequent for diagnostic purposes (Kojima and Yamashita, 2014), and identification of problematic areas for the learners (Smith, 2011) — rather than at making test material in its own right.

Form issue. In addition to scant recognition, Butler's and CAE's concordance-based design seems to deviate significantly from the norm. It is not in the form that is usually recognized by many researchers. Their design lists a few complete sentences, as exemplified in Fig. 1. In contrast, corpus linguists and vocabulary researchers refer to concordancing differently. By concordance, they normally refer to a set of truncated lines where a linguistic unit of interest is centered. Some examples include Sinclair (1991), Cobb (1997), Partington (1998), Nation (2001), Teubert and Čermáková (2004), Smith et al. (2008), Flowerdew (2009) and Tribble (2013). This is the patterning which concordancers display on-screen by default (e.g. at the Corpus of Contemporary American English (COCA), http://corpus.byu.edu/coca/). Such an alignment is shown in the seven-line concordance of Fig. 2 below, where the centered blanks represent a Key-Word-In-Context (KWIC), to which only one word choice (B choke) will make the lines meaningful and correct (more details to be discussed in Section 2.1).

Fig. 2 A ConCloze item

Kunlaphak Kongsuwannakul http://mc.manuscriptcentral.com/llc 
From the common practice of concordance retrieval reviewed above, it is apparent that concordance lines are in most cases arranged centrally, which is the reason why this paper will deal with the centrally arranged version only. Through such centered alignment, learners' attention is drawn to the focal feature (Flowerdew, 1993). It is also 'easier to read and analyze' (Schmitt, 2000, p. 78). Therefore, from a cautious viewpoint, multiple complete sentences (Butler's and CAE's) may not trigger the same cognitive processes as multiple centered and truncated lines do. That is, learners could approach the two item formats differently. This leaves the widely recognized form of concordancing (i.e. the centrally arranged, truncated version) utterly under-researched for language testing purposes.

Discussion question and hypothesis. For the above reasons of 1) little recognition of the item type and 2) no language testing research on the institutionalized presentation of concordancing, the present paper aims to point out some potentially practical applications of ConCloze. A ground for more research — and thus a warrant for the current paper-is that there is currently growing interest in multi-word lexical units as a future trend for vocabulary studies, but 'there has been little systematic work on how such lexical units should be assessed... [to the degree that several types of such units] will require contextualized test formats' (Read, 2012, p. 318, italics mine). Since critical theoretical considerations can lead to actual research questions in second language acquisition (Ionin, 2012), it is hypothesized in this paper that the item type can be realized in several possible ways as various item formats (also called item variants), accompanied by tangible and illustrative examples. The formats are then supplemented with the discussion of word knowledge involved. In doing so, with a 'methodmongering' line of inquiry (Petre and Rugg, 2010), the discussion also touches upon their potential implications for language pedagogy and assessment, and corpus-linguistic practices, and hence could ignite many a research question for fellow researchers and practitioners. Figure 3 below portrays the interrelationship among the discussion issues in this paper, all encompassed by their potential contribution to language acquisition. As Fulcher (2013) and Shohamy (2000) reiterated, second language acquisition and language testing seem to be distinctly yet undesirably separated. Therefore, the discussion of these applications and prospects is timely: it presents a converging point between 
innovative pedagogical tools (i.e. concordancing and corpus-based inquiries) and language testing at the time when computer technology and the internet are becoming widely accessible at an unprecedented rate.

Fig. 3 Relationship of issues in the discussion

The structure of the article $^{1}$ is as follows. The next section (Section 2) deals with practical applications of the item type. It is structured according to a variety of item formats. A theoretical explanation in relation to word-knowledge components involved in doing the items is then provided in Section 3. Afterwards, potential implications of these applications for language pedagogy and assessment, and corpus construction and annotation are presented in Section 4. The paper ends with concluding remarks and recommendations for future research (Section 5).

\section{Practical applications of ConCloze tests}

Taylor (1953) is the creator of the concept cloze procedure. He coined the term cloze-likened to "to close (or hind) something' - to assimilate this cognitive process into the Gestalt theory, in which the human mind seeks to restore the completion of a pattern when some of its elements are missing (just as when we do a jigsaw puzzle or fill in the blank within an incomplete sentence). Applying the cloze procedure to concordance-based material, the following (Sections 2.1 and 2.2) are some possible item formats that are based on the clozing of specific linguistic units within concordances. While I fully recognize that a KWIC can represent a multi-word linguistic unit (Sinclair, 1991; Someya, 2000; Sinclair, 2003; Schmitt and Carter, 2004; Schmitt et al., 2004b), for conciseness, I will confine the discussion to the single-word level only. 


\subsection{Response-selected items}

There are a variety of response-selected item formats that ConCloze can support. The variation in design can take place in either the item prompt (the stimulus given to test takers, i.e. the retrieved concordance) or the stem and options (the question and choices to choose from), or a combination of both. As Fulcher and Davidson (2007) contended, item and test specifications are largely a matter of common sense, where choices in the design can be based on the experience and evidence so as to justify particular decisions being made. The perspectives presented here on the item formats are therefore theoretical and prototypical in nature. There could always be tweaks and modifications of testcraft added to the item and test specifications, and the corresponding items.

The simplest application of the notion of cloze procedure is the presentation of a concordance prompt with all the KWIC occurrences blanked out (just as Fig. 2 is). The prompt is followed by a question stem which urges the selection of one correct answer. The classic way of providing options to the test takers is a four-option type, though two-, three-, and five-option modes are also possible. Figure 4 below illustrates this fundamental item format.

\section{Fig. 4 A ConCloze item (noun as key)}

It should be noted that Figs. 2 and 4 are produced by the same item specification. Both of the two items provide four options of a close semantic field (block, choke, shake, and sob in Fig. 2, and alternative, choosing, offer, and possibility in Fig. 4). The use of a close semantic field stems from Sinclair's (1991) corpus-derived finding that even words or expressions with similar meanings can behave differently in terms of usage. In ConCloze, if the test takers have a profound knowledge of the vocabulary tested, they should be able to differentiate such nuances of meaning and use (see also Section 3 for word-knowledge components). The major distinction between the two test items lies essentially in the part of speech of the KWIC (and hence all the distractors): Fig. 2 inquires of the test 
takers a verb in context whereas Fig. 4 focuses on a noun in context. Regardless of the keys asked, both require the test takers to select a single-word response that can fit into the respective concordances.

Since concordance output offers an extended unit of meaning which is brought about in the company of the KWIC (Flowerdew, 2009), a logical item variation to Fig. 4 is to make use of this extension in a meaning unit more profoundly. Specifically, it is very challenging to transform the single-word options into meaning-based options. Figure 5 below illustrates this idea of the item construction. This item variant has options of meanings (or definitions), not the word forms, for the test takers to select. As each ConCloze prompt forms a newly constructed semantic set, this meaning set allows the meaning of an option to be matched with.

Fig. 5 A meaning-selected ConCloze item

As introduced at the beginning of this section, there can be modifications of item-test specifications, and resultant items. In Fig. 5, a slight modification is made to the concordance prompt: a non-word is in place of the blanks in order to add an additional element of puzzle solving. Yet, the concept of the KWIC clozing is still retained. Also, the four options still offer a close domain of lexical semantics — semantic affinity which the lexicon of and meanings in a particular language have (Paradis, 2013). While the shared semantic field of all these options can be represented collectively as deceiving someone, the dictionary-styled definitions in the options (stemming from fool (Option A), betray (Option B), con (Option C), seduce (Option D)) show nuances in meaning and use, and thus require of the test takers a deeper knowledge and understanding of the words in actual use. This must be to the degree that the definition that best fits all the concordance lines can be selected correctly. This closeness in semantic sets of the options is conceptually derived from the same postulate by Sinclair (1991) underlying Figs. 2 and 4. 
To further illustrate how tweaks can be practically incorporated to the item construction, Fig. 6 below is produced out of a virtually identical item specification for the ConCloze item type. The only tweak added is that the distractors are not necessarily from a close semantic field. This could make the item easier, as the test takers will only need to 1) formulate from a given concordance a simple, approximate hypothesis — rather than a fine-tuned one like that of Fig. 4 and Fig. 5-of the meaning of a likely KWIC, and 2) match it with the most plausible meaning of a word form provided in the options.

Fig. 6 A semantically open, word-selected ConCloze item

In Fig. 6, the key is Option A apparent. While the distractors are all adjectives just like the key, the test takers would not need an in-depth analysis of the concordance to arrive at an answer. Option B can be easily eliminated in the item process, as capable is normally not followed by a thatclause (the only exception found in the COCA is the construction so capable + that-clause). The same reason also applies to Options $\mathrm{C}$ and $\mathrm{D}$, as the adjective form of dynamic and the word flexible do not normally precede a that-clause. Nor are they compatible with robbery in concordance line 4 , for example.

The last response-selected item format to be discussed here is one with a variation in both the item prompt and the selection of item options. One possible way of doing so is to assimilate the notion of matching into the ConCloze item type. That is, in this item variant, not only do the test takers have to differentiate between options of a close semantic domain, but they will need to assign the right options to the matching concordances. Figure 7 below illustrates this idea.

Fig. 7 A matching-style, word-selected ConCloze item 
So far, the current discussion has sought to illustrate how the ConCloze item type can be applied as several response-selected item formats. As highlighted in this section, test takers' finetuned hypothesis-making is certainly needed for the completion of this kind of test task. This implies that the item type can be very useful for quality-oriented vocabulary assessment (as opposed to vocabulary-size measurement) (cf. Schmitt, 2010), since it requires not only the form-meaning knowledge of the vocabulary tested, but also the knowledge of how and what context the words are routinely used in. As introduced earlier, Section 3 will discuss a theoretical model likely underlying the item type.

\subsection{Response-constructed items}

In addition to response selection, the ConCloze item type also has potential for supporting responseconstructed item designs. Essentially, the supply type (i.e. response-constructed one) is when the test takers have to create an answer or produce a test task response or performance of their own. Therefore, Figs. 2, and 4-6 above are all capable of converting into response-constructed items. For example, a supply-type counterpart modeled after the format of Fig. 5 can result in Fig. 8 below. In it, the test takers will need to 1) work out the core meaning of the non-word KWIC (gack in Fig. 8) in light of the extended unit of meaning carried by most or all of the concordance lines given, and then 2) express that deduced meaning in words. Simple answers expected for this item include 'get something' and 'to achieve or obtain'.

Fig. 8 A meaning response-constructed ConCloze item

Kunlaphak Kongsuwannakul http://mc.manuscriptcentral.com/llc 
As will be elaborated in terms of word-knowledge components underlying the item type in Section 3, there are multiple dimensions of word knowledge involved in ConCloze. It is therefore not unusual to ask the test takers about aspects of a target word other than form recognition. In Fig. 8, this has manifested itself as the meaning aspect of the KWIC (disguised in the form of a non-word). Hence, another possible format could be that which inquires of the test takers the function aspect of the KWIC. In Fig. 9 below, the test takers are required to provide the most likely genre where the non-word KWIC is used (which represents the verb fool serving in the fiction genre).

Fig. 9 A genre response-constructed ConCloze item

Another example of the response-constructed item format is a classic design: one concordance with the KWIC blanked out is given to the test takers, and they are asked to restore the KWIC. This can be considered a counterpart to Fig. 4, but it can be relatively challenging, particularly when the KWIC is of a higher frequency level. For example, Fig. 10 below requires of the test takers one word (i.e. bathe, a $4 \mathrm{~K}$ word in the British National Corpus (BNC)-COCA) that can fit all the provided concordance lines meaningfully. Not only do the test takers have to form a plausible hypothesis about the missing KWIC that is compatible with the extended unit of concordance-derived meaning, but they will also need to choose the right word from their mental lexicon and write it correctly as well.

Fig. 10 A word response-constructed ConCloze item

Since the supply type is usually harder than the selection type, ceteris paribus, a simple but effective technique for curbing the difficulty level is to provide the first letter as a clue to the expected 
test task performance. This is in line with the arguments advanced by Raatz and Klein-Braley (1981) when they attempted to improve the traditional cloze tests by introducing C-tests. The results of giving such word-part clues in the ConCloze tests could be lower item difficulty and greater objectivity in grading. Figure 11 below illustrates this idea of incorporating the C-testing technique into ConCloze.

Fig. 11 A C-test-style, response-constructed ConCloze item

Up to this point, the current theoretical discussion has both presented some practical applications of the ConCloze item type and briefly introduced a theoretical model underlying it. The next section will discuss the model more in detail. In doing so, it will also seek to point out some potential uses of the item type in language-classroom settings.

\section{Word knowledge in the ConCloze test items}

As reviewed in Read (2000), context-dependent vocabulary test formats have higher face validity and more favorable psychometric properties than context-independent counterparts. Since the ConCloze item type presents concordance as prompts containing contextual clues - and thus deserving the label as such - it should definitely be valid and psychometrically sound at face value at the minimum. To examine the item type more closely for its indispensable construct validity (Messick, 1988, 1989) as well as other psychometric properties, however, one must first have appropriate theoretical models in mind so as to establish a comprehensive validation framework. And that is the purpose of this section: to investigate a conceptual model that can likely account for the area of knowledge involved in this item type. 
As contended at the beginning of Section 2, a ConCloze item seems to operate on the basis of clozing a KWIC, either by blanking it out or by replacing it with a non-word. The next crucial question about the viability of this item type is therefore what aspects or areas of knowledge which the test takers would examine in order to answer a test item of this kind (i.e. to figure out the clozed KWIC). Nation's $(2001,2005)$ word-knowledge model—or in his terms amount of learning burden a learner has for a word or lemma — offers a useful paradigm for this issue. It can help to clarify the roles of the KWIC and systematize the theoretical formulation of the item-type construct.

According to Nation (2005, p. 49), "what is involved in knowing a word" can be divided into three aspects (form, meaning, use), each having three distinct components. Since the responseselected items (Figs. 2, and 4-6) are in principle natural extensions of response-constructed sample items (Figs. 8-11), and therefore represent the testing of word-knowledge recognition without the confounding influence of knowledge production (e.g. knowing the answer but misspelling it), Table 1 below will describe all the components from Nation's model related to receptive word knowledge only. Given the receptive item designs being discussed, I therefore apply Nation's model to the current conceptual discussion by marking its relevant components with asterisks.

Table 1 Nation's (2001, p. 27, adapted) categorization of receptive word knowledge

\begin{tabular}{lll}
\hline Aspect & Component & Question Asked \\
\hline Form & Spoken & What does the word sound like? \\
& Written & What does the word look like?* \\
& Word parts & What parts are recognizable in this word?* \\
\hline Meaning & $\begin{array}{l}\text { Form and meaning } \\
\text { Concept and referents }\end{array}$ & $\begin{array}{l}\text { What meaning does this word form signal?* } \\
\text { What is included in the concept?* }\end{array}$ \\
\hline Ase & Associations & What other words does this make us think of?* \\
\hline & Collocations & What words or types of words occur with this one?* \\
& $\begin{array}{l}\text { Constraints on use } \\
\text { (register, frequency ...) }\end{array}$ & $\begin{array}{l}\text { Where, when, and how often would we expect to meet this } \\
\text { word }\end{array}$ \\
\hline * indicates a clear relationship with doing a ConCloze item.
\end{tabular}


From Table 1, a substantial body of word knowledge is likely involved in the ConCloze item type. First of all, the written word form of a plausible KWIC must be recognized and differentiated from its counterparts (i.e. those forms of the other item options or distractors). As morphemes (e.g. word stem, derivational morpheme) may be used for narrowing the scope of choice selection, the word parts can also play a role in the item processing. This should be true particularly when a learner's internalized language knowledge is still largely incomplete. They could attempt to 'crack' the meaning of unknown words through recognizable word parts. A real example from the literature is when some students try to decode the words like discourse and nevertheless but end up translating into without direction and never less (Bensoussan and Laufer, 1984).

In addition to the word-form aspect, the meaning of each word form must be deciphered. That is, not only will the word form be recognized, but its meaning must be worked out. This should remain true in both the choice selection and elimination. As thousands of words in English have more than one meaning, their nuance of concepts and referents are also likely to be determined. The fittest meaning for each option must be assigned in light of a given concordance and other item options to the degree that a judicious selection of an answer can be made. As an illustration of this point, students will need to determine the meaning referent of interest in the option sets loan, rate, credit and motive, attention, attraction.

Particular attention should also be drawn to the association component of the word-meaning aspect. It is the frequently co-occurring word associations that will likely make the learners think of the most plausible KWIC. This clearly means that even seemingly synonymous KWICs can have slightly varied sets of word associations and definable semantic fields (Sinclair, 2003; Scott and Tribble, 2006). Therefore, the current conceptual discussion can fit into this component of Nation's word-knowledge model in such a way that the meaning of a suitable KWIC candidate is in interaction with a given set of word associations. This interplay will be valid to the extent that their match accepts or rejects the hypothesis formed out of the learners' cloze process. The acceptance and rejection thus vary and depend on the primed efficiency of the competence of individual learners in determining the semantic associations. Classic examples would include the negative cause and notorious vs. the 
positive generate and famous, in respective order, where the words themselves bear limited denotational senses but can potentially set off a series of connotations.

With regard to the word-use aspect in Nation's model, the theoretical discussion of the item type clearly needs a careful consideration of concordances. In this respect, the concordances function as the contextual clues and impose their constraints onto the match with a KWIC. The grammatical constraints - also known as colligations — control which item option could be structurally viable (e.g. interested in vs. afraid of). The collocational constraints control that semantically and compositionally (e.g. bordering on + an undesirable state (Schmitt and Carter, 2004, p. 8), and high season vs. peak hours). And the use constraints control it in terms of, for example, register and the likelihood of occurrence (i.e. where and about what, as in the formal exhausted vs. the informal knackered). These dimensions of constraints in word use clearly rely on the learners' priming-induced sensitivity to contextual variations and thus their sensibility in judging the preferred usage and semantic set of each KWIC. In other words, the internalized priming does not only contribute to the acquisition of individual words and their contextual constraints (linguistic and extralinguistic alike), but it also accounts for the multidimensional functionality of a concordance prompt and its options for selection in the ConCloze item type. Given the multiple aspects of word knowledge for the test takers to use in the item type, this obviously means that the prompt and the options are in a two-way interaction: the prompt imposes a manifold constraint on which option to be its valid answer while each option exhibits lexically primed preferences that 1) distinguish itself from the other options and 2) seek for compatible lexicogrammatical fields and pragmatically definable sets.

To conclude, a KWIC in the ConCloze item type is an integral component of several naturally interconnected linguistic sequences. By deleting or clozing it, learners' cloze process is activated in accord with their primed competence of the key word so as to restore it materially. The most suitable word form is selected and its shade and referent of meaning is determined by the webs of those sequences, which demand compatibility in terms of structure, collocation, semantic field, and register. These dimensions and components are intricately interwoven and thus not mutually exclusive. 


\section{Implications of ConCloze tests}

In the previous part, the ConCloze item type has been discussed in terms of its various practical applications and potential language processes involved in performing the test tasks. In this part, some significant implications of this item type for language pedagogy and assessment in general and corpus building and annotation in particular will be discussed.

\subsection{Reconceptualized language pedagogy}

From the argument presented thus far, human language is clearly not composed of individual words arranged linearly into texts and talks out of purely open choice. There are the idiomatic sequences operating interconnectedly behind the idiosyncratic features and messages (Sinclair, 1991). In fact, the phenomenon of formulaic language is one of the most significant modern-day discoveries in linguistics, and accordingly is only gaining momentum in such related disciplines as language teaching and learning (Schmitt, 2010). Since use of prefabricated routines is also garnering greater recognition as 'a hallmark of the highest stages of language mastery' (Schmitt, 2010, p. 145), its potential role in language testing - as a likely, direct consequence of more ConCloze tests to be developed and implemented — can add fresh impetus to the realization of formulaic language in language pedagogy (cf., for example, Alderson and Banerjee, 2001 for washback or impact of testing on language pedagogy). In other words, as put forward earlier that 1) language learning and language testing need to be more connected, and 2) the ConCloze tests have potential for the testing of highlevel language mastery, more operational uses of the tests will result in there being a reconceptualization of the paradigms for language pedagogy. This will be to the extent that curricula and teaching practices can, and usually try to, prepare the students for the language tests that they are about to take (Fulcher and Davidson, 2007).

While the potential impacts may not be a total paradigm shift in language pedagogy, the further implications of getting the phenomenon of multiword units into the limelight — particularly 
through the force of language testing - can be fairly serious, if not grave, for many language practitioners and learners alike. From a very broad point of view, the impact of a lexical syllabus (that in the curricula promoting the learning of 1) words on the basis of corpus-derived frequency and 2) interdependence of lexis and grammar (Szudarski, 2013)) can become even more significant. As many language teachers and course designers have never been trained lexicogrammatically (ibid.), the introduction of this data-driven syllabus and corpus-based findings into their 'comfort zone' can implicate hard work for them to accommodate themselves to. That is, a number of teachers still do not know how to effectively incorporate corpora and concordances into their classes, and concordancebased materials are not readily purchasable either (Moran and Diniz, 2005). They themselves thus need training in their use (Lee, 2011). Moreover, as corpora and concordances promote discoverybased language learning (Nation, 2001), the role of language teachers must be facilitative rather than authoritative (Stevens, 1991), for example.

At the conceptual level, those teachers previously unfamiliar with Sinclair's idiom principle, for instance, will not only need to learn the concepts of interconnection between words and their definable semantic fields, but also need to realize such theoretical modeling in their instruction in a tangible yet accessible way for their students. According to Andrews (2008), concordancing can contribute to developing and improving the teachers' own language awareness (i.e. what they know about the language they teach). As a consequence, they need to seek As a result, their-hands-on training in how to explore language corpora and command a concordancer to 1) compare word and phrase frequencies, 2) retrieve concordance lines, and 3) compute the strength of associationand experience of corpus based queries (= questions in the form of commands given to a computer program, in most cases a concordancer, to carry out) will be indispensable for a given phrase, for example. Without their own grasp of corpus insights, their ability to enhance a meaningful corpusbased learning experience for their students seems out of the question.

On the part of the students, not only will they, if no experience of corpora at all, need to strive harder to understand the rich information of vocabulary in real contexts which language corpora and concordances can offer (cf. Nation, 2001), but they will also have to truly attain the high-level 
mastery of formulaic sequences so that they are capable of dealing with the ConCloze tests. As this paper delivers a case for these item formats as discrete-point measures of collocations and word associations with concordance lines sourced from multiple genres (except in Fig. 9), the article automatically implies that the item type potentially reduces bias towards particular subject matters (i.e. tests appearing easier or more difficult merely because of the familiarity with the topics of the texts, rather than because of actual competence) and achieves a greater scale of test fairness. In other words, use of multiple-sourced concordance lines in ConCloze cancels out the advantage and disadvantage to the test takers in terms of topical familiarity, thereby being fair to them all. On the contrary, should test developers wish to test the students' sensibility for genre features (as exemplified in Fig. 9, where one genre is aimed as part of the testing purpose) and write the item and test specifications accordingly, the item type is also malleable to genre-based assessment. Both of the genre-sourced orientations (varied or specific) suggest that in order to successfully deal with this item type, the students must acquire a breadth and depth of word knowledge indeed.

As Hoey (2000) pointed out, words are associated with their surrounding contexts, and thus it is a danger posed to the students when they learn from vocabulary lists instead of words in contexts. That is, rather than through context-deprived word lists, vocabulary learning and teaching should be done through high exposure to authentic text, which is naturally filled with intricate patterns of idiomatic language. Since the acquisition of formulaic sequences takes time and their learning success rates can vary from person to person (Dörnyei et al., 2004; Schmitt et al., 2004a), it is therefore a judicious investment of time and educational resources to train the language learners to explore corpora and concordances from their early stages of language literacy development. This will allow a maximum effectiveness of concordances in raising awareness of patterned features such as collocation and semantic prosody in the long run. As corpus-based material is amenable to self-study (Kongsuwannakul, 2013) and there exist many online corpora available on the internet (Schmitt, 2010), equipping the learners with skills in manipulating corpus queries should consequently be equivalent to sustainable lifelong learning. For example, well-trained 'corpus-literate' learners should understand the basics of a large collection of texts commonly termed 'corpus', and know how to 
search for collocates of a particular word in question. As a basic search skill, they would, for instance, key in a wild card $\left(^{*}\right)$ in the collocate box at the COCA for adjectives to combine with the word 'variety', so as to assist in their writing homework (in which they should find out that they can confidently write ‘wide variety' and 'limited variety' but would frown upon ‘big variety' and 'narrow variety'). For more corpus-based classroom applications, see O'Keeffe et al. (2007), for example.

\subsection{Word knowledge profiling and evaluation}

Apart from the implications for a reconceptualized language pedagogy outlined in the previous section, those related to 'data-driven assessment' - as a simple analogy to data-driven learning (Johns, 1991) - are also plausible. As Read (2000) stipulated, vocabulary assessment must take multi-word units into consideration. Since the ConCloze tests are driven by authentic language data containing multi-word sequences, the tests can therefore fulfill the need for incorporating such prefabricated units for assessment purposes.

Generally speaking, vocabulary knowledge can be assessed in two practical ways: quantity and quality (Schmitt, 2010). For example, the Vocabulary Levels Test is a measure for evaluating the size of vocabulary known to a learner (Schmitt et al., 2001). As a universally accepted test, it gives an estimate of how many words each learner knows. However, with regard to the qualitative dimension, there are still a limited number of available tests. Read's (1993) Word Associates Format and Gyllstad's (2009) COLLEX and COLLMATCH are among the few, which are all contextindependent though. Therefore, the ConCloze item type potentially makes a new measure for worddepth evaluation. In particular, as presented that it taps into higher-order components of word knowledge (such as semantic and use constraints), a well-validated ConCloze test is likely to assess, for example, word associates in context systematically and accurately.

Note that word association is a useful word-knowledge component that can effectively discriminate advanced learners from adult native speakers (Zareva, 2004). If such a test as ConCloze is developed and validated for assessment purposes, it means that language testers will have a bigger 
toolkit of item designs that are available for establishing a standard language-performance benchmark for evaluating the competence of the students in contrast to that of the native speakers. Equipped with validated test interpretations, the ConCloze item designs can be, for instance, part of a vocabularyquality assessment inventory (the dimensions approach (Read, 1997, cited in Schmitt, 1999, p. 194)). It can help to diagnose or construct a learner's profile of word-knowledge components. This can be highly informative about the extent the learner has mastered the lexicon of the English language.

Since vocabulary, according to the Firthian school of thought, is vital to other language skills such as reading and writing (Hill, 2000), and is generally a good predictor of those areas of language competence (Schmitt, 2010), a 'test suite'—certainly with the ConCloze tests included — that focuses on assessing multiple dimensions of vocabulary competence would be a realistic and resourceefficient approach to assessing learners' language competence. Moreover, from what the future holds for international English for Academic Purposes (EAP) tests, 1) testing grammatical skills alone will not be sufficient and 2) recognizing or producing "appropriate academic discourse" is ideal (Clapham, 2000, p. 518), the various ConCloze formats would appear to be a wise choice of evaluating the students' receptive-productive knowledge of academic vocabulary in terms of its usage in authentic contexts.

As Fulcher and Davidson (2007) illustrated, item and test specifications can be laid out and written such that they break down the test tasks into multiple parameter-like components (e.g. the correct option described as being +abstract or -abstract word). The same is true for ConCloze tests. Language testers can design the items so that they cover a wide range of componential features of word knowledge and its dimensions (cf. Section 3). This is very useful for portraying a student's performance in a vocabulary-proficiency test battery, since, for example, some students who know a good deal of vocabulary in terms of form and meaning (e.g. knowing that plump, stout, and fat are synonyms) may actually not know much how and in what contexts the words should be used properly (e.g. knowing chubby is a synonym for overweight but using it in an academic paper for discussing a crisis of adult obesity in the UK). 
As language testers must know detailed properties of their test instruments (Chalhoub-Deville and Turner, 2000), it seems that they will need to carefully describe and consider (and even reconsider) task features which may impact on the item construct representation and test performance. This is another massive implication: the constructs that we 'believe' are tested in a given vocabulary test may in fact be underrepresented or irrelevant if all the word-knowledge aspects and components are taken into account. The implementation of the ConCloze tests, which can highlight the unique and varied nature of word knowledge in real use, could draw special attention to fine-grained item and test specifications to the extent that the language testers must ensure that the aspects and components described in the test interpretations truly represent what the vocabulary tests being validated claim to measure. For example, a set of test items is described in the item specification as intended for assessing the academic-vocabulary adjectives, but the options of these items are in fact from the fiction genre in terms of their corpus-based frequencies. These items are therefore construct-irrelevant for the testing purposes.

On the whole, as the ConCloze item type emphasizes the reality in vocabulary use that knowing a word is composed of several aspects and components, it urges that a comprehensive assessment of vocabulary knowledge be undertaken accordingly. On this account, it also strenuously advises test designers and language testers to cope with equally considerable challenge of ensuring those components validly measured by their already existing test toolkit. This is so because, based on the relatively recent, corpus-based discoveries of variation in word associations (different words with varied collocational and semantic sets [for more information, see Biber, 1993; Biber et al., 1996; Netzer et al., 2009; Greaves and Warren, 2010; Michelbacher et al., 2011, for example]), all the longexisting tests may not elicit observed scores adequate for extrapolating to the domain of word knowledge. This could hence cause quite a stir in the assessment of vocabulary knowledge in general, as it ultimately implies a reconsideration of all item designs and tests already in use. 


\subsection{Fine-grained corpus and concordance annotations}

As Alderson (1996) suggested long ago, language testers can retrieve corpus texts for constructing tests of authentic language. Moreover, the very phenomenon of word associations - as suggested in this paper for its relationship with the ConCloze item type - can vary in accordance with genres and even between empirical and intuition sources. Accordingly, since ConCloze relies on corpus output and concordances, a well-designed corpus and fine-grained concordance annotations can contribute greatly to the empirical construction and delivery of this item type and even of other item types, such that they can reflect the varied nature of language in real use and the objectives of individual assessment events.

Smith et al. (2008) investigated possibilities and limitations of top-down approaches to manually annotating corpora and concordances (e.g. metatextual information like age and educational level of the speaker or writer, and concordance categories like discourse marker and polarity). While they found that, for rigorous descriptions of language use and resultant theories, there are still a number of restrictions on concordance annotations (such as corpus texts and their markings separated), annotations of this kind are on the way. In fact, as suggested here, such annotations are worth researchers' effort and needed not only for a full understanding of variation in real language use, but also for manipulating the ConCloze test construction. Specifically, since writing test items should be evidence-based in every step taken (Fulcher and Davidson, 2007), language testers can enter corpus queries in such a way that they can craft their tests suitably for their testing purposes. For example, test writers for a course in microfinance can limit their search of interest to the bankingrelated usage in the newspaper genre. This will be both time-saving and representative of the target domain, thereby ensuring confidence in text typicality.

Such targeted searches are possible only when corpora and concordances are annotated in detail. In other words, corpora should be built purposively and concordances annotated specifically yet multidimensionally. This should therefore be the other implication carried by wider use and research of the ConCloze formats. Extensively researched ConCloze-and indisputably other item 
types demanding text authenticity—would urge more fine-grained annotations of corpora and concordances. Not only can corpus linguists themselves benefit from this increased control and more in-depth analysis of the corpus data, but they will also assist other linguistic disciplines in pushing the boundaries of exploring human language. As Smith et al. (2008) pleaded desperately, software developers and linguists need to collaborate much more closely and actively if detailed top-down annotations of corpora and concordances are to be a reality.

Moreover, in the future when computer technology (especially artificial intelligence) becomes more advanced, it is foreseeable that automatic test construction and delivery (as in internet-based computer-adaptive tests) can be carried out by commanding the test-administration server to select and create tests based on certain algorithms, for example. As specialized corpora (such as language learner corpora and learner-built corpora) may be more pedagogically relevant to the classroom settings, another example of the implications of ConCloze for automated test construction is to preset the linguistic features that are to be tested (such as hedging devices), present particular native versions of concordances to the test takers online, and ask them to perform the test tasks (e.g. identifying wrong usage of a particular hedging expression in the non-native ConCloze, or choosing the most appropriate choice of hedging devices that best fit the given native-speaker concordances).

\section{$5 \quad$ Concluding remarks}

Concordances have been used for enhancing learning experience by some language teachers and practitioners for over two decades (e.g. Tribble and Jones, 1990; Stevens, 1991; Aston, 2002; Gaskell and Cobb, 2004). In tandem with corpora, concordances are regarded as reliable resources of target language that facilitate autonomous learning. However, they have rarely been used for testing and assessment purposes. Therefore, this paper has attempted to point out their potential in this respect. In the overall picture, this can inform the teachers of the value of these item prototypes and their direct applicability to their classes. Language learners will not only learn through exposure to corpora of authentic language, but they will also benefit equally from the reinforcement of their learned language 
skills and knowledge through testing. On this account, the values of corpus-based inquiries will no longer be confined to language learning. They will be expanded to assessing and providing feedback on the learning and instruction. In other words, ConCloze as a potentially new context-dependent item type by Read's (2000) categorization will be added to the toolkit of language testers and teachers.

As 1) the ConCloze tests can highlight the interrelated nature of words and their surrounding contexts, and 2) both language pedagogy and vocabulary assessment should therefore reflect this linguistic reality, a final note is that there should be considerably more research on the item type. Nation's (2001) multiple word-knowledge aspects have highlighted the interconnection from the point of view of vocabulary learning, and therefore ConCloze can emphasize this nature from the languagetesting viewpoint. It gives new impetus to integrated-skills assessment (cf. Plakans, 2012). As to my ongoing study, I am carrying out a construct validation, focusing on the substantive aspect of this item type, with a view to developing a response-selected ConCloze test of academic vocabulary. Since the item type has been little investigated in the field of language testing despite its potential as a pragmatic solution to testing the multidimensional constraints of natural language integratedly, urgent research agenda could be wide-ranging, from curricular relevance to value implications, and from test utility to social consequences. For example, future research can focus on the relevance of a ConCloze design to a particular language curriculum, seeking the areas that have been overlooked or could not be measured in the past. As ConCloze appears to be the only context-dependent item type existing nowadays that can focus exclusively by means of a multitude of test items on specific areas of word knowledge (depending on the item and test specifications), it is not an overstatement to assert that ConCloze will be a staple part of corpus-derived applications in language testing.

\section{References}

Alderson, J.C. (1996). Do corpora have a role in language assessment? In Thomas, J. and Short, M. (eds.), Using corpora for language research: Studies in the honor of Geoffrey Leech. Essex: Longman, pp. 248-59. 
Alderson, J.C. and Banerjee, J. (2001). Language Testing and Assessment (Part 1). Language

Teaching, 34: 213-36.

Andrews, S.J. (2008). Teacher language awareness. In Encyclopedia of Language and Education. 2nd ed. New York: Springer Science \& Business Media, pp. 287-98.

Aston, G. (2002). Getting one's teeth into a corpus. In Tan, M. (ed.), Corpus Studies in Language

Education. Bangkok: Institute for English Language Education Press, pp. 131-43.

Bensoussan, M. and Laufer, B. (1984). Lexical Guessing in Context in EFL Reading Comprehension. Journal of Research in Reading, 7(1): 15-31.

Biber, D. (1993). Co-Occurrence Patterns among Collocations: A Tool for Corpus-Based Lexical Knowledge Acquisition. Computational Linguistics, 19(3): 531-8.

Biber, D., Conrad, S. and Reppen, R. (1996). Corpus-Based Investigations of Language use. Annual Review of Applied Linguistics, 16: 115-36.

Butler, J. (1991). Cloze Procedures and Concordances: The Advantages of Discourse Level Authenticity in Testing Expectancy Grammar. System, 19(1-2): 29-38.

Cambridge English Language Assessment. (2010a). Cambridge English: Advanced (CAE): What's in the Exam? Available online at http://www.cambridgeenglish.org/exams-andqualifications/advanced/whats-in-the-exam/ (accessed December 14, 2013).

Cambridge English Language Assessment. (2010b). Find Free Resources: Cambridge English: Advanced (CAE): Use of English. Available online at http://www.cambridgeenglish.org/images/26800-cae-use-of-english-sample-test.pdf (accessed November 15, 2013).

Kunlaphak Kongsuwannakul http://mc.manuscriptcentral.com/llc 
Chalhoub-Deville, M. and Turner, C.E. (2000). What to Look for in ESL Admission Tests:

Cambridge Certificate Exams, IELTS, and TOEFL. System, 28(4): 523-39.

Clapham, C. (2000). Assessment for Academic Purposes: Where Next? System, 28: 511-21.

Clavel-Arroitia, B. and Fuster-Márquez, M. (2014). The Authenticity of Real Texts in Advanced English Language Textbooks. ELT Journal, 68(2): 124-34.

Cobb, T. (1997). Is there any Measurable Learning from Hands-on Concordancing? System, 25(3): $301-15$.

Dörnyei, Z., Durow, V., and Adolphs, S. (2004). Individual differences and their effects on formulaic sequence acquisition. In Schmitt, N. (ed.), Formulaic sequences: Acquisition, processing and use. The Netherlands: John Benjamins, pp. 87-106.

Flowerdew, J. (1996). Concordancing in language learning. In Pennington, M.C. (ed.), The power of CALL. Texas: Athelstan, pp. 97-113.

Flowerdew, J. (1993). An Educational, Or Process, Approach to the Teaching of Professional Genres. ELT Journal, 47(4): 305-16.

Flowerdew, L. (2009). Applying Corpus Linguistics to Pedagogy: A Critical Evaluation. International Journal of Corpus Linguistics, 14(3): 393-417.

Fulcher, G. (2013). The SLA-testing Interface. Available online at http://languagetesting.info/features/sla/\%26assessment.html (accessed November 20, 2013).

Fulcher, G. and Davidson, F. (2007). Language Testing and Assessment. Oxon, UK: Routledge.

Gaskell, D. and Cobb, T. (2004). Can Learners use Concordance Feedback for Writing Errors? System, 32: 301-19.

Kunlaphak Kongsuwannakul http://mc.manuscriptcentral.com/llc 
Greaves, C. and Warren, M. (2010). What can a corpus tell us about multi-word units? In O'Keeffe, A. and McCarthy, M. (eds.), The Routledge handbook of corpus linguistics. London: Routledge, pp. $212-26$.

Gyllstad, H. (2009). Designing and evaluating tests of receptive collocation knowledge: COLLEX and COLLMATCH. In Barfield, A.W. and Gyllstad, H. (eds.), Researching Collocations in Another Language: Multiple Interpretations. Hampshire, UK: Palgrave Macmillan, pp. 153-70.

Hargreaves, P. (2000). Collocation and testing. In Lewis, M. (ed.), Teaching collocation: Further developments in the lexical approach. Massachusetts, USA: Thomson, pp. 205-23.

Hill, J. (2000). Revising priorities: from grammatical failure to collocational success. In Lewis, M. (ed.), Teaching collocation: Further developments in the lexical approach. Massachusetts, USA: Thomson, pp. 47-69.

Hoey, M. (2000). A world beyond collocation: New perspectives on vocabulary teaching. In Lewis, M. (ed.), Teaching collocation: Further developments in the lexical approach. Massachusetts, USA: Thomson, pp. 224-43.

Ionin, T. (2012). Formal theory-based methodologies. In: Mackey, A. and Gass, S.M. (eds.), Research Methods in Second Language Acquisition: A Practical Guide. West Sussex: Blackwell Publishing, pp. $30-52$.

Johns, T. (1991). Should You be Persuaded -- Two Samples of Data-Driven Learning Materials. ELR Journal, 4: 1-16.

Kojima, M. and Yamashita, J. (2014). Reliability of Lexical Richness Measures Based on Word Lists in Short Second Language Productions. System, 42: 23-33.

Kongsuwannakul, K. (2013). Concordance-Based Material as a Form-Focused Solution to Constituent Misordering. The International Journal of Pedagogy and Curriculum, 19(2): 57-74.

Kunlaphak Kongsuwannakul http://mc.manuscriptcentral.com/llc 
Lee, H. (2011). In Defense of Concordancing: An Application of Data-Driven Learning in Taiwan. Procedia Social and Behavioral Sciences, 12: 399-408.

Messick, S. (1989). Validity. In: Linn, R.L. (ed.), Educational measurement. 3rd ed. New York: American Council on Education; Collier Macmillan, pp. 13-103.

Messick, S. (1988). The once and future issues of validity: Assessing the meaning and consequences of measurement. In: Wainer, H. and Braun, H.I. (eds.), Test validity. New Jersey: Lawrence Erlbaum Associates, pp. 33-45.

Michelbacher, L., Evert, S. and Schütze, H. (2011). Asymmetry in Corpus-Derived and Human Word Associations. Corpus Linguistics and Linguistic Theory, 7(2): 245-76.

Moran, K. and Diniz, L. (2005). Teaching with Concordances. On CALL, 22(2).

Nation, I.S.P. (2005). Teaching Vocabulary. The Asian EFL Journal, 7(3): 47-54.

Nation, I.S.P. (2001). Learning Vocabulary in another Language. Cambridge, UK: Cambridge University Press.

Netzer, Y., Gabay, D., Goldberg, Y. and Elhadad, M. (2009). Gaiku: generating Haiku with word associations norms. Proceedings of the Workshop on Computational Approaches to Linguistic Creativity (CALC '09). Stroudsburg, PA, USA.

O'Keeffe, A., McCarthy, M. and Carter, R. (2007). From Corpus to Classroom: Language use and Language Teaching. Cambridge: Cambridge University Press.

Paradis, C. (2013). Lexical semantics. In Chapelle, C.A. (ed.), The Encyclopedia of Applied Linguistics (Vol. 6). West Sussex, UK: Wiley-Blackwell, pp. 3347-56.

Park, K. (2014). Corpora and Language Assessment: The State of the Art. Language Assessment Quarterly, 11(1): 27-44.

Kunlaphak Kongsuwannakul http://mc.manuscriptcentral.com/llc 
Partington, A. (1998). Patterns and Meanings: Using Corpora for English Language Research and Teaching. Amsterdam: John Benjamins.

Petre, M. and Rugg, G. (2010). The Unwritten Rules of PhD Research. 2nd ed. Berkshire, UK: Open University Press.

Plakans, L. (2012). Writing integrated items. In Fulcher, G. and Davidson, F. (eds.), The Routledge Handbook of Language Testing. Oxon: Routledge, pp. 249-61.

Raatz, U. and Klein-Braley, C. (1981). The C-Test - A modification of the cloze procedure. In Culhane, T., Klein-Braley, C., and Stevenson, D.K. (eds.), Practice and Problems in Language Testing. Colchester, UK: Department of Language and Linguistics, University of Essex, pp. 113-38.

Read, J. (2012). Piloting vocabulary tests. In Fulcher, G. and Davidson, F. (eds.), The Routledge Handbook of Language Testing. Oxon: Routledge, pp. 307-20.

Read, J. (2000). Assessing Vocabulary. Cambridge: Cambridge University Press.

Read, J. (1993). The Development of a New Measure of L2 Vocabulary Knowledge. Language Testing, 10(3): 355-71.

Schmitt, N. (2010). Researching Vocabulary a Vocabulary Research Manual. Basingstoke: Palgrave Macmillan.

Schmitt, N. (2000). Vocabulary in Language Teaching. Cambridge: Cambridge University Press.

Schmitt, N. (1999). The Relationship between TOEFL Vocabulary Items and Meaning, Association, Collocation and Word-Class Knowledge. Language Testing, 16(2): 189-216.

Schmitt, N. and Carter, R. (2004). Formulaic sequences in action: An introduction. In Schmitt, N. (ed.), Formulaic sequences: Acquisition, processing and use. The Netherlands: John Benjamins, pp. $1-22$.

Kunlaphak Kongsuwannakul http://mc.manuscriptcentral.com/llc 
Schmitt, N., Dörnyei, Z., Adolphs, S. and Durow, V. (2004a). Knowledge and acquisition of formulaic sequences: A longitudinal study. In Schmitt, N. (ed.), Formulaic sequences: Acquisition, processing and use. The Netherlands: John Benjamins, pp. 54-86.

Schmitt, N., Grandage, S. and Adolphs, S. (2004b). Are corpus-derived recurrent clusters psycholinguistically valid? In Schmitt, N. (ed.), Formulaic sequences: Acquisition, processing and use. The Netherlands: John Benjamins, pp. 126-51.

Schmitt, N., Schmitt, D., and Clapham, C. (2001). Developing and Exploring the Behaviour of Two New Versions of the Vocabulary Levels Test. Language Testing, 18(1): 55-88.

Scott, M. and Tribble, C. (2006). Textual Patterns: Key Words and Corpus Analysis in Language Education. Amsterdam: John Benjamins.

Shohamy, E. (2000). The Relationship between Language Testing and Second Language Acquisition, Revisited. System, 28: 541-53.

Sinclair, J.M. (2003). Reading Concordances: An Introduction. London: Pearson Longman.

Sinclair, J.M. (1991). Corpus, Concordance, Collocation. Oxford, UK: Oxford University Press.

Smith, N., Hoffmann, S. and Rayson, P. (2008). Corpus Tools and Methods, Today and Tomorrow: Incorporating Linguists' Manual Annotations. Literary and Linguistic Computing, 23(2): 163-80.

Smith, S. (2011). Learner Construction of Corpora for General English in Taiwan. Computer Assisted Language Learning, 24(4): 291-316.

Someya, Y. (2000). Online business letter corpus KWIC concordancer and an experiment in datadriven learning/writing. The 3rd International Conference of the Association for Business

Communication. Doshisha University, Kyoto, Japan. Available online at www.someyanet.com/kamakuranet/DDW Report.pdf (accessed Dec 16, 2013).

Kunlaphak Kongsuwannakul http://mc.manuscriptcentral.com/llc 
Stevens, V. (1991). Classroom Concordancing: Vocabulary Materials Derived from Relevant, Authentic Text. English for Specific Purposes, 10: 35-46.

Szudarski, P. (2013). Lexical syllabus. In Chapelle, C.A. (ed.), The Encyclopedia of Applied Linguistics (Vol. 6). West Sussex, UK: Wiley-Blackwell, pp. 3356-60.

Taylor, L. and Barker, F. (2008). Using corpora for language assessment. In Shohamy, E. and Hornberger, N.H. (eds.), Encyclopedia of Language and Education. 2nd ed. New York: Springer Science \& Business Media, pp. 241-54.

Taylor, W.L. (1953). "Cloze Procedure": A New Tool for Measuring Readability. Journalism Quarterly, 30: 415-33.

Teubert, W. and Čermáková, A. (2004). Corpus Linguistics: A Short Introduction. London: Continuum.

Tribble, C. (2013). Concordancing. In Chapelle, C.A. (ed.), The Encyclopedia of Applied Linguistics (Vol. 2). West Sussex, UK: Wiley-Blackwell, pp. 871-9.

Tribble, C. and Jones, G. (1990). Concordances in the Classroom: A Resource Bookfor Teachers. Harlow: Longman.

Zareva, A.P. (2004). A model of lexical knowledge assessment of adult native and non-native speakers of English: Structure of the mental lexicon of advanced and intermediate non-native speakers of English. Ph.D. thesis, University of Georgia, Athens.

Kunlaphak Kongsuwannakul http://mc.manuscriptcentral.com/llc 


\begin{abstract}
Note
1 This is not my thesis article. While I did produce the contents covered in this article during my doctoral research, the thesis has changed its course of investigation and developed into a study which specifically validates the construct of the substantive component of a ConCloze format only. In a way, the paper only presents peripheral issues of the research.
\end{abstract}

Kunlaphak Kongsuwannakul http://mc.manuscriptcentral.com/llc 
Each of the sentences below has the same word missing. Fill in the blank with the correct word.

A.

1. Fortunately we ..... have large amounts of exploitable potential on which to capitalize.

2. There is no question, however, that food production will have to be raised . . . . higher to help feed the world's growing population.

3. This ... does not solve the problem.

4. Here's hoping you're ..... in your old flat by the time this letter reaches you.

Fig. 1 One of Butler's (1991, p. 36) ConCloze item prototypes $277 \times 74 \mathrm{~mm}(120 \times 120$ DPI $)$ 
For the following questions, read the given texts and decide which answer (A, B, C, or D) best fits all the gaps. Mark your answers on the separate answer sheet.

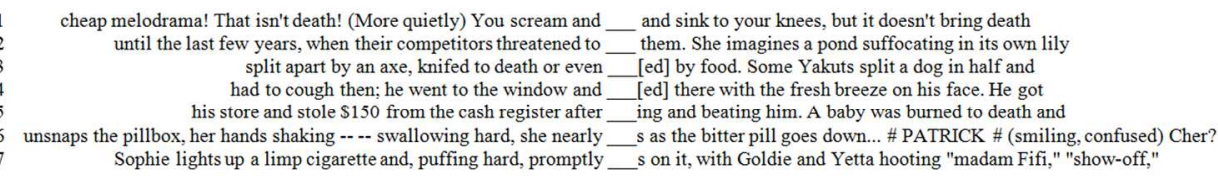

All the lines above miss the same word. Which of the following should be that word?
A block
B $\operatorname{chok}(\mathrm{e})$
C shak $(e)($ shook/shaken $)$
D $\operatorname{sob}(\mathbf{b})$

Fig. 2 A ConCloze item $277 \times 92 \mathrm{~mm}(120 \times 120 \mathrm{DPI})$ 
Fig. 3 Relationship of issues in the discussion $274 \times 73 \mathrm{~mm}(120 \times 120 \mathrm{DPI})$ 

A alternative
B choosing
Coffer
D possibility

Fig. 4 A ConCloze item (noun as key) $277 \times 64 \mathrm{~mm}(120 \times 120$ DPI $)$ 
Fig. 5 A meaning-selected ConCloze item $272 \times 109 \mathrm{~mm}(120 \times 120 \mathrm{DPI})$ 
All the lines above miss the same word. Which of the following should be that word? A apparent
B capable
C dynamic
D flexible

Fig. 6 A semantically open, word-selected ConCloze item $276 \times 62 \mathrm{~mm}(120 \times 120 \mathrm{DPI})$ 
The three sets of text above miss three different words. Fill out all the blanks with the words given below.

adjust blink focus wink

Fig. 7 A matching-style, word-selected ConCloze item $271 \times 104 \mathrm{~mm}(120 \times 120$ DPI $)$ 
Fig. 8 A meaning response-constructed ConCloze item $271 \times 71 \mathrm{~mm}(120 \times 120 \mathrm{DPI})$ 
Fig. 9 A genre response-constructed ConCloze item

$270 \times 70 \mathrm{~mm}(120 \times 120 \mathrm{DPI})$

not absolutely safe at this hour. Also, her housecoat wouldn't gack a soul. She was running around in her nightclothes, basically. you're needed but also when you're not. \# TROI \# You can't gack an empath, Captain. I know exactly when I'm needed. Picard and down the mountain - we'll go on forever trying to gack each other. Your girl is a fine dancer, I say. to catch up with her artist friends, but she didn't gack him. She wanted him wed. // He'd heard Palmerson had a the trapped force. Venera examined the map. "We have to gack them into making the wrong choice," she said. "Yes, but people learn to see through you. My husband stopped being gacked by my bright, perky deflections. His gaze bored straight through She returned his gaze without backing off. She was hard to gack. Again, briefly, he was struck by a sudden fear of

Gack is an imaginary word. Where do you think you can find it in frequent use? 
All the blanks above miss the same word. Fill them out.

Fig. $10 \mathrm{~A}$ word response-constructed ConCloze item $275 \times 50 \mathrm{~mm}(120 \times 120$ DPI $)$ 
Fig. 11 A C-test-style, response-constructed ConCloze item $270 \times 60 \mathrm{~mm}(120 \times 120 \mathrm{DPI})$ 